\title{
ECMO Plus Intra-arrest PCI - Excellent Option in a 'no other Option' Situation
}

\author{
Manoj Agny* \\ Consultant Cardiac \& Transplant Surgeon, Mumbai
}

Submission: January 30, 2019; Published: March 21, 2019

*Corresponding author: Manoj Agny, Consultant Cardiac \& Transplant Surgeon, Hospitals - Jaslok, Saifee, Nanavati, Khar Hinduja, Mumbai, India

\begin{abstract}
A major cause of sudden unexpected death is cardiac arrest. Despite a properly performed cardiopulmonary resuscitation, only a minority of patients who suffer cardiac arrest are able to be meaningfully resuscitated. ECPR (an alternative CPR method in which Extracorporeal Membrane Oxygenation (ECMO) is used) along with intra-arrest PCI can be effective lifesaving dual procedures for patients in whom conventional Cardio Pulmonary Resuscitation (CPR) cannot achieve the return of spontaneous circulation. Also, important would be the fact that near optimal temporal perfusion of the other vital organs is ensured during the course of this high-risk situation needing a quick salvage.

Keywords: Cardio pulmonary resuscitation, Vital organs, Quick salvage, Coronary syndrome, Cardiac arrest

Abbrevations: CPR: Cardio Pulmonary Resuscitation; ACS: Acute Coronary Syndrome; ECLS: Extracorporeal Life Support; ROSB: Return of Spontaneous Heartbeat; ROSC: Return of Spontaneous Circulation; IABP: Intra-Aortic Balloon Pump
\end{abstract}

\section{Overview}

A high incidence of acute coronary syndrome is reported in patients with cardiac arrest. The mortality rate is very high, and PCI success in patients without return of spontaneous heart beat has not been established. In such situations of refractory cardiac arrest due to an Acute Coronary Syndrome (ACS) and no other obvious non-cardiac cause of arrest, an emergent coronary angiography following an institution of rapid-response ECMO along with an intra-arrest PCI would be associated with a higher survival rate in patients who are unresponsive to conventional CPR.

\section{Brief Introduction to ECMO}

ECMO is essentially of two types - Venoarterial (V-A ECMO) and Venovenous (V-V ECMO). V-A ECMO is primarily used in refractory post cardiotomy cardiogenic shock situations wherein there is a potentially reversible cardiac condition. It can also be used as a bridge to a ventricular assist device or cardiac transplantation. Herein higher $\mathrm{PaO} 2$ is achieved at lower perfusion rates as pulmonary circulation is bypassed. A drop in pulmonary pressures is achieved as the cardiac function is optimized to aid the flailing systemic circulation.

In Venovenous ECMO, pulmonary blood flow is maintained as lung recovery is enhanced under more apt conditions. $\mathrm{PaO} 2$ is lower than the VA mode and higher flow rates are needed. It does not aid in cardiac support and is thus primarily useful in situations where the heart function is well preserved and essentially lung support is desired.

In view of so many uses in varying clinical situations a new and more appropriate name, Extracorporeal Life Support (ECLS), has been coined.

\section{Clinical trials}

A multicenter cohort study [1] involving rapid-response ECMO plus intra-arrest PCI was conducted in Japan in 86 patients with acute coronary syndrome who were unresponsive to conventional CPR. Emergency coronary angiography was performed in $94 \%$ of the cases with $71 \%$ undergoing intra-arrest PCI. The rates of Return of Spontaneous Heartbeat (ROSB), 30-day survival, and favorable neurological outcomes were 88\%, 29\%, and $24 \%$ respectively. A shorter time interval from collapse to the initiation of ECMO - 40 minutes versus 54 minutes - translated into improved into improved 30-day survival. They concluded that in ECPR situations, a significantly high percentage of patients receiving intra-arrest PCI achieve ROSB and are associated with improved outcomes. 


\section{Conclusion}

ECMO provides adequate temporary perfusion to organs in cardiac arrest patients before Return of Spontaneous Heartbeat (ROSB). It increases the success rate of defibrillation in cardiac arrests, prevents re-arrest due to myocardial dysfunction following CPR and enables subsequent interventions [2]. In contrast to conventional CPR where Return of Spontaneous Circulation (ROSC) is an important end point, in ECPR, ROSB is the surrogate point since patients are supported by artificial circulation via ECMO. ROSB is defined as the presence of ventricular wall motion as identified by echocardiography and a pulse pressure of more than $5 \mathrm{~mm} \mathrm{Hg}$ without the use of an Intra-Aortic Balloon Pump (IABP).

Highly encouraging results such as a $29 \%$ 30-day survival and $24 \%$ favorable neurological outcome are seen with rapidresponse ECMO, PCI, and/or hypothermia in cardiac arrest patients who were otherwise unresponsive to conventional CPR and who traditionally are assumed to have an extremely unfavorable prognosis.

On the basis of the encouraging data coming to the fore on this front, randomized studies of intra-arrest PCI are needed. Approval by the hospital ethics committee should be sought prior to the undertaking of a huge high-risk dual procedure like this.

Rapid-response ECMO plus intra-arrest PCI is feasible and associated with improved outcomes in patients who are unresponsive to conventional cardiopulmonary resuscitation.
The SHOCK (Should We Emergently Revascularize Occluded Coronaries for Cardiogenic Shock) trial [3] reported that early revascularization should be strongly considered in cardiogenic shock scenarios [3]. A team from China has reported successful PCI with ongoing continuous mechanical chest compression with LUCAS device in a patient who presented with cardiac arrest following acute myocardial infarction [4].

Going a step further, in patients with refractory cardiac arrest, the question that begs serious thought is: Should emergency revascularization be done in occluded coronaries for cardiac arrest patients using rapid-response ECMO and PCI? S C A R E - P C I Trial!

\section{References}

1. Kagawa E, Dote K, Kato M, Sasaki S, Nakano Y, et al. (2012) Should we emergently revascularize occluded coronaries for cardiac arrest? Rapid-response extracorporeal membrane oxygenation and intraarrest percutaneous coronary intervention. Circulation 126(13): 1605-1613.

2. Laurent I, Monchi M, Chiche JD, Joly LM, Spaulding C, et al. (2002) Reversible myocardial dysfunction in survivors of out-of-hospital cardiac arrest. J Am Coll Cardiol 40(12): 2110-2116.

3. Hochman JS, Sleeper LA, Webb JG, Sanborn TA, White HD, et al. (1999) The SHOCK Investigators. Early revascularization in acute myocardial infarction complicated by cardiogenic shock. N Engl J Med 341(9): 625-634.

4. Zhang ZP, Su X, Liu CW, Song D, Peng J, et al. (2015) Continuous Mechanical Chest Compression-assisted Percutaneous Coronary Intervention in a Patient with Cardiac Arrest Complicating Acute Myocardial Infarction. Chin Med J(Engl) 128(6): 846-848.

\begin{tabular}{l} 
Your next submission with Juniper Publishers \\
will reach you the below assets \\
- Quality Editorial service \\
- Swift Peer Review \\
- Reprints availability \\
- E-prints Service \\
- Manuscript Podcast for convenient understanding \\
- Global attainment for your research \\
- Manuscript accessibility in different formats \\
( Pdf, E-pub, Full Text, Audio) \\
- Unceasing customer service \\
Track the below URL for one-step submission \\
https://juniperpublishers.com/online-submission.php \\
\hline
\end{tabular}

